\section{Carbohydrate antigen 27-29}

S. Holdenrieder ${ }^{1}$ und P. Stieber ${ }^{2}$

${ }^{1}$ Institut für Laboratoriumsmedizin, Deutsches Herzzentrum München, München, Deutschland

${ }^{2}$ Institut für klinische Chemie, Klinikum der Universität München (LMU), München, Deutschland

Synonym(e) CA 27-29; Cancer antigen 27-29

Englischer Begriff carbohydrate antigen 27-29

Definition Carbohydrate antigen $27-29$ ist ein $300 \mathrm{kDa}$ schweres muzinöses Glykoprotein namens MUC-1. Das gleiche Muzin wird auch von $>$ Carbohydrate antigen 15-3Assays erkannt.

Struktur Carbohydrate antigen 27-29 ist ein hochmolekulares Kohlenhydratantigen der Milchfettkügelchen-MuzinFamilie, das mittels des monoklonalen Antikörpers B27-29 detektiert wird.

Molmasse $300 \mathrm{kDa}$.

Synthese - Verteilung - Abbau - Elimination Immunhistologisch wird CA 27-29 von Mammakarzinomen exprimiert, ebenso von normalem Brustdrüsengewebe. Außerdem fand es sich in Adenomen und Karzinomen des Kolons sowie bei Adenokarzinomen anderer Genese.

Funktion - Pathophysiologie CA 27-29 kann wie alle Muzinmarker zur Therapiekontrolle und Nachsorge des Mammakarzinoms eingesetzt werden. Wegen nicht vorhandener Komplementarität zu CA 15-3 und MCA ( $\triangleright$ Mucinlike cancer associated antigen) ist eine Kombination nicht sinnvoll. Als Zweitmarker empfiehlt sich CEA ( $\triangleright$ Carcinoembryonales Antigen).
Untersuchungsmaterial - Entnahmebedingungen Plasma, Serum, Liquor, Aszites, Pleurapunktat.

Analytik $>$ Enzymimmunoassay (EIA), \ Radioimmunoassay (RIA), Immunradiometrischer Assay (IRMA), - Elektrochemilumineszenz-Immunoassay (ECLIA).

Konventionelle Einheit U/mL (kU/L).

Referenzbereich - Erwachsene $<25 \mathrm{kU} / \mathrm{L}$ (methodenabhängig).

Indikation Therapiekontrolle und Nachsorge beim Mammakarzinom (mit CEA).

Interpretation Neben dem Mammakarzinom kann CA 27-29 auch bei anderen Karzinomen des Kolons, des Magens, der Leber, der Lunge, des Kopf-Hals-Bereichs, des Ovars, der Prostata sowie bei Non-Hodgkin-Lymphomen erhöht sein.

Hinsichtlich benigner Erkrankungen sind gutartige Lebererkrankungen herauszuheben. Auch bei Mastopathien, benignen pulmonalen, gastrointestinalen und gynäkologischen Erkrankungen können erhöhte Werte gefunden werden.

Diagnostische Wertigkeit Mammakarzinom: Therapiemonitoring, Rezidiverkennung (mit CEA).

\section{Literatur}

Stieber P, Heinemann V (2008) Sinnvoller Einsatz von Tumormarkern. J Lab Med 32:339-360

Sturgeon CM, Duffy MJ, Stenman UH et al (2008) National Academy of Clinical Biochemistry laboratory medicine practice guidelines for use of tumor markers in testicular, prostate, colorectal, breast, and ovarian cancers. Clin Chem 54:e11-e79 